\title{
Blood screen findings in a 2-year cohort of newly arrived refugees to Sydney, Australia
}

\author{
Choisung C Ngo ${ }^{a}$, Christine Maidment ${ }^{a}$, Lisa Atkins ${ }^{a}$, Sandy Eagar ${ }^{a}$ and \\ Mitchell M Smitha,b,c
}

a NSW Refugee Health Service, South Western Sydney Local Health District, Australia

${ }^{b}$ Guest Editor, Public Health Research \& Practice, Issue 1, 2018

c Corresponding author: mitchell.smith1@health.nsw.gov.au

\section{Article history}

\section{Publication date: March 2018}

Citation: Ngo CC, Maidment C, Atkins L, Eagar S, Smith MM. Blood screen findings in a 2-year cohort of newly arrived refugees to Sydney, Australia. Public Health Res Pract. 2018;28(1):e2811804. https://doi. org/10.17061/phrp2811804

\section{Key points}

- Prevalence of chronic infectious diseases, including latent tuberculosis infection and hepatitis $B$, is low in refugees from the Middle East

- Strongyloides seropositivity was found in $4.1 \%$ of those screened; this is an important condition to detect and eliminate

- Vitamin D deficiency remains very common in refugee settlers

- Targeted HIV testing found no cases. The authors recommend risk-based HIV screening only, in this prescreened population of resettled refugees

\section{Abstract}

Objectives: To describe the prevalence of certain health conditions in newly arrived refugees to Sydney, Australia, and thereby help inform screening practices.

Study type: A clinical audit of routinely collected pathology results.

Methods: Demographics and pathology results from a nurse-led health assessment program for newly arrived refugees during 2013 and 2014 were analysed. Prevalences of screened conditions were calculated, and compared by country of birth and other demographic features. A specific category was created for those from Middle Eastern countries, for comparative analysis.

Results: Pathology results were analysed for 3307 people from 4768 seen by the assessment program (69.4\%). Anaemia was found in $6 \%$ of males and $7.6 \%$ of females. Vitamin D deficiency ( $<50 \mathrm{nmol} / \mathrm{L}$ ) was detected in $77.5 \%$. Chronic hepatitis B was found in only $1.7 \%$ but in more than $10 \%$ of people from Burmese and Tibetan backgrounds. Strongyloides seropositivity was found in $4 \%$. Among the subset tested for hepatitis $\mathrm{C}$ antibody, $0.5 \%$ were positive. No human immunodeficiency virus (HIV) infections were detected.

More than $75 \%$ of the study population was from Middle Eastern countries. Compared with refugees from other regions, this subset had less anaemia (in females), more vitamin D deficiency, less chronic hepatitis B and less strongyloides seropositivity.

Conclusions: People from refugee backgrounds have differing risks of conditions, based on demographics, migration history and prior screening. Postarrival testing should be tailored to each family and individual. Results of screening should be constantly reviewed and the approach updated based on findings. We support, in particular, the Canadian approach of only retesting HIV in refugees from countries with a high prevalence of infection (>1\%). 


\section{Introduction}

In recent years, Australia has accepted 13750 refugees annually through its humanitarian migration program. This number will gradually increase to 18750 by 2019. The Australian Government also allocated a one-off intake of 12000 places over 2016 and 2017 for refugees fleeing the crises in Syria and Iraq.

Health assessment of resettled refugees is important. Many come from persecuted minorities, and have endured war or civil unrest, overcrowding, unsanitary environments and repeated displacement, leaving them susceptible to psychological trauma and communicable infections. With conflict and the breakdown of healthcare systems, healthcare may be inadequate, and medical conditions may go undiagnosed and undertreated. Additionally, certain conditions such as thalassaemia and vitamin $\mathrm{D}$ deficiency are more common in certain ethnic groups. ${ }^{1}$

When refugees arrive in Australia, individuals and families are encouraged to undertake an initial health assessment. In New South Wales (NSW), this may be done through a refugee nurse program that exists in key settlement areas. Alternatively, a general practitioner (GP) may be the first port of call, or a combination of the two, depending on local service delivery models.

The most recent (2016) guidelines for health assessment of people from refugee-like backgrounds outline the prevalence of various conditions by region, but there is a lack of data for people from the Middle East. ${ }^{1}$

This study reports on the prevalence of conditions found during screening undertaken in 2013 and 2014 by the NSW Refugee Health Service (RHS) Nurse Program based in metropolitan Sydney. Because most resettlement during this period was of refugees from the Middle East, notably Iraq, this study updates current knowledge of common health issues found in Middle Eastern refugees settling in Australia, to inform approaches to the ongoing intake from that region.

\section{Predeparture health assessment}

Intending permanent migrants to Australia, including refugee applicants, undergo a mandatory immigration medical examination 3-12 months before departure. In 2013 and 2014, this included a history, physical examination, a chest $X$-ray if aged 11 years or older, and human immunodeficiency virus (HIV) testing if aged 15 years or older. ${ }^{2}$ Syphilis testing was introduced at the end of $2015 .^{3}$ Other tests may be ordered, if indicated.

Around 3 days before departure, funded refugee entrants are offered a voluntary departure health check, which includes: assessment of 'fitness to fly'; testing and treatment for malaria (depending on port of departure); presumptive treatment for helminths; immunisation for measles, mumps and rubella (MMR); and possibly other immunisations. ${ }^{4}$

\section{Postarrival assessment}

Since late 2012, newly arrived refugees settling in the Sydney metropolitan region have been offered a health assessment through the NSW RHS Nurse Program. The aim of this initial assessment is to facilitate transition into mainstream healthcare. It includes a review of health issues, including physical, psychological, dental and vaccination status, and some baseline investigations. Screening is based on the World Health Organization principles for screening for disease and the Australasian Society for Infectious Diseases (ASID) refugee health guidelines (2009 version at that time). 5,6

Additional tests are ordered for symptomatic individuals, in consultation with an RHS medical officer, if required. Other circumstances would also alter the approach; for example, a pregnant woman would have routine antenatal screening. Nonroutine investigations are not examined in this review.

\section{Methods}

This clinical audit was performed on routinely collected data from the RHS Nurse Program in Sydney (see Supplementary Tables 1 and 2 for details of screening tests, available from: hdl.handle.net/2123/17910). Individual, generic consent was obtained to collect, store and evaluate this data. Results and demographics for 2013 and 2014 were downloaded from the pathology provider's online database. Information on country of birth, which is not included in the pathology database, was inserted through a data-matching process, with manual checking where inconsistencies occurred.

For analysis, a category called 'Middle East' was formed, combining those born in Iraq, Syria, Iran, Lebanon, Kuwait and Saudi Arabia. Egypt was not included because most refugees born in Egypt were of Sudanese ethnicity.

Selected statistical significance values have been included, calculated using a chi-square test for comparing proportions. We did not perform age standardisation for this descriptive paper.

\section{Results}

There were approximately 8270 humanitarian settlers in metropolitan Sydney during 2013 and 2014. Of these, 5222 were referred to the RHS Nurse Program; 4768 attended and 3307 underwent pathology testing.

Demographics for those tested are shown in Figure 1 below, and Supplementary Tables 3 and 4 (available from: hdl.handle.net/2123/17910). People from Iraq, Iran, Syria, Afghanistan, Pakistan, Tibet, India and Myanmar (Burma) collectively accounted for more than $90 \%$ of arrivals during the study period. 
Figure 1. Number and percentage of total cohort tested, by country of birth $(n=3307)$

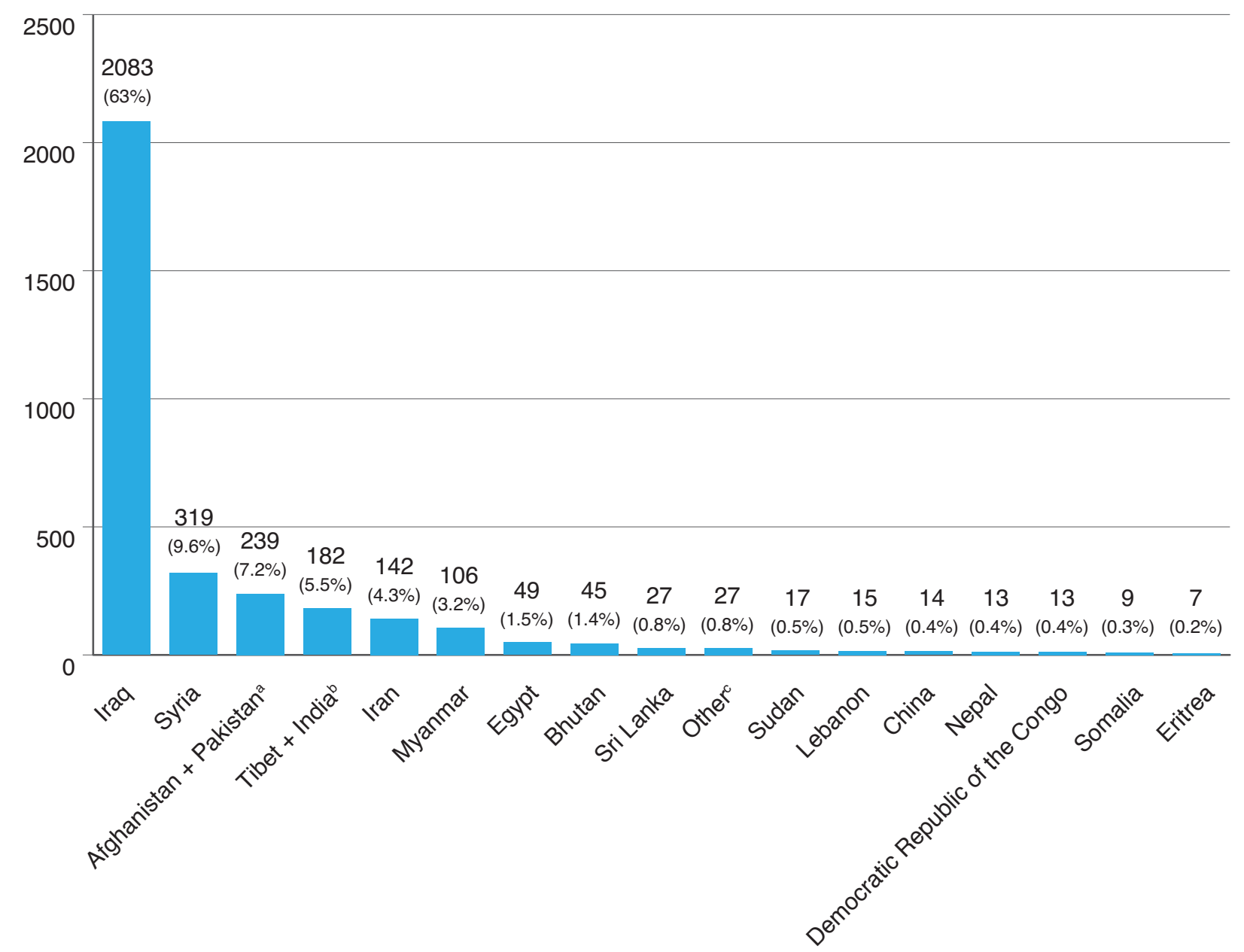

${ }^{a}$ Afghanistan and Pakistan are grouped together because resettled refugees from Pakistan are generally children born to Afghan refugees in exile.

b Tibet and India are grouped together because resettled refugees from India are generally children born to Tibetan refugees in exile.

c 'Other' comprises Vietnam, Sierra Leone, Nigeria, Kuwait, Guinea, Fiji, Ethiopia, Tanzania, Saudi Arabia, Liberia and Cambodia. 


\section{Results from routine screening tests}

\section{Haemoglobin and ferritin}

Anaemia was detected in $6.0 \%$ of males and $7.6 \%$ of females. Anaemia was particularly prevalent in refugees from Myanmar (12\% of males, $11 \%$ of females), and Tibet and India (11\% of males, $13 \%$ of females). Anaemia in the Middle Eastern population had a prevalence of $5.6 \%$ in males and $6.6 \%$ in females. Iron deficiency was detected in $17 \%$ of anaemic males and $53 \%$ of anaemic females. Thalassaemia trait test results are not reported here.

Table 1. Rates of anaemia, by country of birth and gender

\begin{tabular}{|c|c|c|c|c|}
\hline \multirow[b]{2}{*}{ Country } & \multicolumn{2}{|c|}{$\begin{array}{c}\text { Males } \\
\mathrm{Hb}<120 \mathrm{~g} / \mathrm{L}\end{array}$} & \multicolumn{2}{|c|}{$\begin{array}{c}\text { Females } \\
\mathrm{Hb}<110 \mathrm{~g} / \mathrm{L}\end{array}$} \\
\hline & $n / n t$ & $\%$ & $n / n t$ & $(\%)$ \\
\hline All countries & $100 / 1663$ & 6.0 & $121 / 1590$ & 7.6 \\
\hline Afghanistan + Pakistan & $4 / 136$ & 2.9 & $7 / 97$ & 7 \\
\hline Myanmar & $6 / 51$ & 12 & $6 / 53$ & 11 \\
\hline Iran & $2 / 79$ & 3 & $3 / 61$ & 5 \\
\hline Iraq & $56 / 1011$ & 5.5 & 70/1039 & 6.7 \\
\hline Syria & $13 / 158$ & 8.2 & $10 / 161$ & 6.2 \\
\hline Tibet + India & $11 / 100$ & 11 & $10 / 80$ & 13 \\
\hline Middle East & $71 / 1261$ & $5.6(\mathrm{NS})$ & $83 / 1267$ & $6.6(p<0.01)^{\mathrm{a}}$ \\
\hline
\end{tabular}

$\mathrm{Hb}=$ haemoglobin; $n=$ number with $\mathrm{Hb}<120 \mathrm{~g} / \mathrm{L}$ (males) or $<110 \mathrm{~g} / \mathrm{L}$ (females); $\mathrm{NS}=$ not significant; $n t=$ number tested for Hb level

a Lower than women from non-Middle Eastern countries

\section{Vitamin D}

Vitamin D deficiency $(<50 \mathrm{nmol} / \mathrm{L})$ was detected in $77.5 \%$ of all those tested and $78.7 \%$ of those from the Middle East. Moderate to severe vitamin D deficiency
$(<30 \mathrm{nmol} / \mathrm{L})$ was detected in $34.9 \%$ of the group. Severe vitamin $D$ deficiency $(<12.5 \mathrm{nmol} / \mathrm{L})$ was eight times more common in females than in males (Table 2). In children under 5 years of age, $56.7 \%$ had vitamin D deficiency.

Table 2. Vitamin D deficiency, by gender

\begin{tabular}{lcccccc}
\hline & \multicolumn{2}{c}{ All } & \multicolumn{2}{c}{ Male } & \multicolumn{2}{c}{ Female } \\
\cline { 2 - 7 } Vitamin D level & $n / n t$ & $\%$ & $n / n t$ & $\%$ & $n / n t$ & $1378 / 1593$ \\
\hline$<50 \mathrm{nmol} / \mathrm{L}^{*}$ & $2532 / 3265$ & 77.5 & $1154 / 1672$ & $69.0^{\mathrm{a}}$ & $86.5^{\mathrm{a}}$ \\
$30-49 \mathrm{nmol} / \mathrm{L}^{* *}$ & $1394 / 3265$ & 42.7 & $797 / 1672$ & 47.7 & $597 / 1593$ & 37.5 \\
$12.5-29 \mathrm{nmol} / \mathrm{L}^{* * *}$ & $1064 / 3265$ & 32.6 & $349 / 1672$ & 20.9 & $715 / 1593$ & 44.9 \\
$<12.5 \mathrm{nmol} / \mathrm{L}^{* * *}$ & $74 / 3265$ & 2.3 & $8 / 1672$ & 0.5 & $66 / 1593$ & 4.1 \\
\hline
\end{tabular}

${ }^{*}=$ vitamin D deficiency; ${ }^{* *}=$ mild deficiency; ${ }^{* * *}=$ moderate deficiency; ${ }^{* * *}=$ severe deficiency $7, ; n=$ number deficient in vitamin $\mathrm{D} ;$ $n t=$ number tested for vitamin $\mathrm{D}$ level

a $p<0.0001$

(Further information on vitamin D results can be seen in Supplementary Tables 5, 6 and 7, available from hdl.handle.net/2123/17910.) 


\section{Hepatitis B}

A positive result for hepatitis B surface antigen (HBsAg), meaning probable chronic hepatitis $B$ infection in this context, was found in $1.7 \%$ of those tested. For all countries, $0.2 \%$ of $<10$-year-olds, $0.6 \%$ of $10-19$-yearolds and $2.5 \%$ of $>19$-year-olds were positive for HBsAg. Hepatitis B was far more prevalent in arrivals from Myanmar (11.5\%) and Tibet/India (12.7\%) than in arrivals from the Middle East (0.6\%) (Table 3).

Table 3. HBsAg prevalence, by country of birth and age

\begin{tabular}{lcccccccc}
\hline & \multicolumn{2}{c}{ All ages } & \multicolumn{2}{c}{$<$ 10 years } & \multicolumn{2}{c}{$10-19$ years } & \multicolumn{2}{c}{$>19$ years } \\
\cline { 2 - 8 } Country & $n / n t$ & $\%$ & $n / n t$ & $\%$ & $n / n t$ & $\%$ & $n / n t$ & $\%$ \\
\hline All countries & $57 / 3266$ & 1.7 & $1 / 538$ & 0.2 & $4 / 616$ & 0.6 & $52 / 2112$ & 2.5 \\
Afghanistan + & $4 / 233$ & 1.7 & $0 / 47$ & 0 & $0 / 42$ & 0 & $4 / 144$ & 2.8 \\
Pakistan & & & & & & & & \\
Myanmar & $12 / 104$ & 11.5 & $0 / 17$ & 0 & $0 / 14$ & 0 & $12 / 73$ & 16 \\
Iran & $2 / 139$ & 1.4 & $0 / 13$ & 0 & $0 / 19$ & 0 & $2 / 107$ & 1.9 \\
Iraq & $11 / 2058$ & 0.5 & $1 / 347$ & 0.3 & $0 / 381$ & 0.0 & $10 / 1330$ & 0.8 \\
Syria & $1 / 318$ & 0.3 & $0 / 69$ & 0 & $0 / 83$ & 0 & $1 / 166$ & 0.6 \\
Tibet + India & $23 / 181$ & 12.7 & $0 / 19$ & 0 & $4 / 33$ & 12 & $19 / 129$ & 14.7 \\
Middle East & $14 / 2534$ & 0.6 & $1 / 429$ & 0.2 & $0 / 486$ & 0.0 & $13 / 1619$ & 1.0 \\
\hline
\end{tabular}

$n=$ number positive for HBsAg; $n t=$ number tested

a Lower than people from non-Middle Eastern countries $(p<0.0001)$

Resolved hepatitis B infection (detectable hepatitis $\mathrm{B}$ core antibody [anti-HBc], hepatitis B surface antibody [anti-HBs] $\geq 10 \mathrm{IU} / \mathrm{L}$ and undetectable $\mathrm{HBsAg}$ ) was found in $7.4 \%$ of the cohort. An isolated positive anti$\mathrm{HBc}$ result, often difficult to interpret, was found in 1.4\%. (See Supplementary Table 8, available from hdl.handle. net/2123/17910.)

Anti-HBs at a level of $<10 \mathrm{IU} / \mathrm{L}$, indicating lack of immunity to hepatitis B, was found in $67.1 \%$ of the cohort. Among refugees from the Middle East, there was a trend of lower immunity with increasing age, whereas, among those from Tibet and India, the greater the age, the higher the immunity rates. (See Supplementary Table 9, available from hdl.handle.net/2123/17910.)

Further analysis revealed that $58 \%$ of people from Tibet and India with immunity also had detectable anti-HBc, indicating resolved infection and consistent with higher rates of hepatitis $B$ infection in Tibet and India. In contrast, only $14 \%$ of those tested from the Middle East with immunity had detectable anti-HBc. (See Supplementary Table 9, available from hdl.handle. net/2123/17910.)

\section{Strongyloidiasis}

Strongyloides serology $(\lg G$ ) was positive in $4.1 \%$ and equivocal in $2.2 \%$ of the cohort. Strongyloides was more prevalent in refugees from Myanmar (14.6\%). (See Supplementary Table 10, available from hdl.handle. net/2123/17910.)

\section{Syphilis}

Reactivity to treponemal antibodies was found in 1.1\% of those tested. Numbers tested by country of origin were too small to compare. A positive result does not necessarily mean active infection. (See Supplementary Table 11, available from hdl.handle.net/2123/17910.)

\section{Results from risk-based screening}

\section{Malaria}

Malaria testing was performed on refugees who had lived in, or passed through, countries at risk. Those tested included $72 \%$ (41 of 57 ) of refugees from sub-Saharan Africa who were older than 5 years. Of 185 individuals tested, none had a positive result.

\section{Schistosomiasis}

Schistosomiasis serology was generally tested in people from Africa or Southeast Asia, and was positive in only one person (from Sudan). However, only 25\% (14 of 57) of people from sub-Saharan Africa had this test ordered.

\section{Rubella}

Testing for rubella was recommended for premenopausal females, although some males were also tested. Lack of rubella immunity was found in $9.5 \%$ of the 949 refugees tested. Iran had high nonimmunity rates, at $22 \%$. (See Supplementary Table 12, available from hdl.handle. net/2123/17910.) 


\section{Hepatitis C}

Hepatitis C serology was ordered for people from highrisk countries or with increased risk of bloodborne viruses. Hepatitis $\mathrm{C}$ antibody (anti-HCV) was detected in $0.5 \%$ of those tested, and $0.7 \%$ were reported as indeterminate (meaning the result is unconfirmed). Three of four positive anti-HCV results were in individuals from Myanmar. Although numbers tested from Myanmar were small (51), this detection rate was significantly higher than in those from other countries ( $6 \%$ vs $0.5 \%, p<0.0001$ ). In the Middle Eastern group, only one person in more than 640 tested was anti-HCV positive $(<0.02 \%)$.

Presence of hepatitis $C$ antibody does not necessarily mean current infection. Confirmatory RNA testing is required. No hepatitis $C$ virus RNA testing was performed because the positive and indeterminate patients were referred to GPs for follow-up and further testing, results of which were not readily available.

In terms of coverage, hepatitis C serology was performed in $79 \%$ (33 of 42) of arrivals 15 years and older from sub-Saharan Africa, and 82\% (33 of 41) from Egypt. However, only $30.1 \%$ (479 of 1592) of people originating from all countries with endemic hepatitis $\mathrm{C}$ as per the ASID guidelines ${ }^{1}$ were tested. Interestingly, none of these 479 individuals was positive; two $(0.4 \%)$ were indeterminate. (See Supplementary Table 13, available from hdl.handle.net/2123/17910.)

\section{HIV}

Because this is a prescreened population, HIV was tested only in people aged 15 years or more from subSaharan Africa and the Thailand-Myanmar border region, pregnant women, and others for whom the nurse assessed that testing was prudent. Of 236 'higher risk' individuals tested for HIV-1 and HIV-2 antigen and antibody, none were positive.

HIV testing was performed in $43 \%$ (18 of 42 ) of recent arrivals from sub-Saharan Africa aged 15 years or more. (See Supplementary Table 14, available from hdl.handle. net/2123/17910.)

\section{Latent tuberculosis infection}

At the time of this study, testing for latent tuberculosis infection (LTBI) was performed routinely in those aged 2-5 years and others at risk. The interferongamma release assay for Mycobacterium tuberculosis (QuantiFERON-TB Gold) was performed on 255 individuals. It was positive in 14 (5.5\%) - from Myanmar (2), Iraq (8), Afghanistan (1) and Sudan (3). Four were reported as 'indeterminate' - a failed test result.

By age group, $12 \%$ of $<2$-year-olds, $2.2 \%$ of $2-5$-yearolds and $8 \%$ of $>5$-year-olds tested were positive. (See Supplementary Table 15, available from hdl.handle. net/2123/17910.)

\section{Discussion}

In the two years 2013 and 2014, the NSW RHS Nurse Program saw approximately $58 \%$ of all refugee settlers to Sydney. Others attended GPs for their initial assessment, often taken to the GP directly by sponsoring family members.

Results were not available for those who attended different pathology providers, or those in whom testing was not done, such as refugees who had already seen (and been tested by) a GP before attending the RHS Nurse Program, those younger than 2 years, and a minority who declined pathology.

The cohort was young, with equal numbers of males and females. More than $75 \%$ were from the Middle East.

Anaemia and iron deficiency were common.

Thalassaemia screening is recommended for people with microcytic hypochromic anaemia and adequate levels of ferritin if they are of child-bearing age. In addition, many refugees with iron deficiency without anaemia were found, supporting the view that it is necessary to screen anyone at high risk of iron deficiency and not only those who are anaemic. ${ }^{1}$

Vitamin D deficiency was very common, especially among females. This is possibly linked to social behaviours (clothing and lifestyle) and is not unexpected, because of the cultural backgrounds of many of the refugees. With more than $75 \%$ of people deficient, an argument could be made for supplementing all, rather than testing. The RHS does give vitamin D supplements to all children under 5 years of age (who are now not given blood tests). An economic analysis would indicate whether this approach should also be taken for older refugee children and adults.

Prevalence of chronic infectious diseases was generally low, with a few exceptions. It is also important to note that a positive serological result for many conditions, including syphilis, schistosomiasis and strongyloides, does not necessarily indicate active infection, as these tests can remain positive despite previous treatment or spontaneous resolution of infection.

Chronic hepatitis B was prevalent in certain groups. Detection in new arrivals is important, and current guidelines recommend screening for any adolescent and adult refugees who have not been screened overseas. At the time of these results, patients with chronic hepatitis B were referred to GPs for further investigations and long-term management. This approach has since been improved so that baseline work-up investigations are now completed by the RHS, to facilitate follow-up in primary care.

Isolated positive anti-HBc was found in $1.4 \%$ of the cohort. The most likely reasons for this, in the setting of routine screening, are remote resolved infection with undetectable surface antibodies, false negative infection 
with undetectable HBsAg, or a false positive anti-HBc result. ${ }^{9}$ One study in sub-Saharan African immigrants found that only $3 \%$ of those with isolated anti-HBc had chronic infection. ${ }^{10}$

Hepatitis B immunity was measurable in only onethird of those tested. However, basing immunity on the detection of anti-HBs does not account for those previously immunised but with low levels of anti-HBs, who mount an anamnestic response when challenged with the virus. ${ }^{11}$

Immunity to rubella, where measured, was more than $90 \%$, probably because of international immunisation campaigns and predeparture MMR vaccination.

Positive strongyloides serology in $4 \%$ of those tested is significant because of the importance of excluding a condition that can be fatal in those who develop immune suppression. Individuals with positive serology were treated with two doses of ivermectin. Those who had equivocal results, which may have been false positives, were treated with a single dose of ivermectin, which has been shown to have good efficacy. Stools were not tested in either case because of the low sensitivity of the test and the low side-effect profile of ivermectin. ${ }^{1}$

Prevalences of syphilis, schistosomiasis and hepatitis $\mathrm{C}$ were generally very low. This highlights that targeted testing is appropriate. However, the screening rate for schistosomiasis and hepatitis $C$ in people from target countries was less than ideal, so these prevalences might have been underestimated. A high level of positive or indeterminate results for hepatitis $C$ serology was noted in refugees from Myanmar, compared with previous studies. ${ }^{12}$ Of the five individuals who were positive or indeterminate, four also had evidence of resolved hepatitis B infection. Hence, they appear to have been at significant risk of infection with bloodborne viruses. It should be noted that only low numbers $(n=51)$ were tested, and two results were indeterminate. Testing of all refugees from Myanmar may be warranted until more data are available. Routine testing for syphilis is now part of the immigration medical examination for refugees, so routine syphilis testing after arrival is no longer necessary. ${ }^{3}$

There were no positive malaria results, although only a small number of arrivals required testing. Pretest probability was low because of predeparture treatment of malaria in those from at-risk regions.

HIV testing was risk based rather than routine, yet there were still no positive HIV results. This was not surprising in a prescreened population. However, the current ASID guidelines recommend repeat HIV testing in all people aged 15 years and over. In our experience, this may be overcautious, given the extremely low prevalence in the current major intake region. We support the Canadian evidence based guidelines approach, whereby only those having lived in regions with an HIV prevalence higher than $1 \%$ are offered retesting postarrival. ${ }^{13}$

Positive QuantiFERON-TB Gold results for LTBI are referred for further investigations. This test has lower sensitivity in children aged under 5 , so the prevalence may be an underestimation. ${ }^{14}$ Overseas testing has since been introduced for children aged 2-10 years, and the RHS is now testing adolescents and young adults for LTBI.

Overall, people originating from Middle Eastern countries had significant differences in the prevalence of certain conditions compared with those from other regions, including less anaemia in females, more vitamin $\mathrm{D}$ deficiency, less chronic hepatitis $\mathrm{B}$, and less strongyloides seropositivity.

\section{Conclusion}

Risks of conditions in people from refugee backgrounds depend on age, gender, country or region of origin, places of transit and degree of prior screening. A sophisticated approach to testing is needed, tailored to each family's and individual's migration history and risks. Results of screening should be constantly reviewed, and the approach should be updated based on findings.

There is also a need to avoid overpathologising. Overemphasis on a notion of risk to public health is not warranted and may contribute to negative attitudes towards this already marginalised group.

For the NSW RHS, initial testing aims to detect the most important and most common conditions that may not have been identified by premigration medical processes. This study confirms that, like other refugees, those of Middle Eastern background are at risk of a limited number of conditions that do warrant routine screening.

A further paper will describe chronic diseases and risk factors among Middle Eastern refugee settlers, routine screening for which began after this study.

\section{Competing interests}

None declared

\section{Author contributions}

$\mathrm{CN}$ drafted and revised the manuscript. LA and CM conducted the data analysis and interpretation. SE edited the manuscript and informed its content. MS was responsible for overseeing the process, helping to draft the manuscript, and editing and revision. 


\section{References}

1. Chaves NJ, Paxton G, Biggs BA, Thambiran A, Smith M, Williams J, et al. Recommendations for comprehensive post-arrival health assessment for people from refugeelike backgrounds. 2nd ed. Sydney: Australasian Society for Infectious Diseases; Refugee Health Network of Australia; 2016 [cited 2018 Feb 16]. Available from: www.asid.net.au/documents/item/1225

2. Australian Government Department of Immigration and Border Protection. Canberra: DIBP. Health examinations [cited 2017 Nov 29]; [about 1 screen]. Available from: www.border.gov.au/Trav/Visa/Heal/meeting-the-healthrequirement/health-examinations

3. Australian Government Department of Immigration and Border Protection. Canberra: DIBP. Panel member instructions - Australian immigration medical examinations; 2016 Jul [cited 2017 Nov 29]; [about 1 screen]. Available from: www.border.gov.au/Panelphysicians/Documents/ panel-member-instructions.pdf

4. Australian Government Department of Health [Internet]. Canberra: The Department of Health. Health assessment of refugees and other humanitarian entrants into Australia. Questions and answers; 2014 Apr 17 [cited 2017 Feb 24]; [about 9 screens]. Available from: www.health.gov.au/internet/main/publishing.nsf/Content/ mbsprimarycare_mbsitem_refugees_qanda

5. Wilson JM, Jungner G. Principles and practice of screening for disease. Geneva: World Health Organisation; 1968 [cited 2018 Feb 16]. Available from: apps.who.int/iris/bitstream/10665/37650/17/WHO_ PHP_34.pdf

6. Murray R, Davis J, Krause V, Beverley-Ann B, Lemoh C, Benson J, et al. Diagnosis, management and prevention of infections in recently arrived refugees. Australasian Society for Infectious Diseases. Sydney: Dreamweaver Publishing; 2009.
7. Nowson CA, McGrath JJ, Ebeling PR, Haikerwal A, Daly RM, Sanders KM, et al. Vitamin D and health in adults in Australia and New Zealand: a position statement. Med J Aust. 2012;196(11):686-7.

8. Paxton GA, Teale GR, Nowson CA, Mason RS, McGrath JJ, Thompson MJ, et al. Vitamin D and health in pregnancy, infants, children and adolescents in Australia and New Zealand: a position statement. Med J Aust. 2013;198(3):142-3.

9. Al-Mekhaizeem KA, Miriello M, Sherker AH. The frequency and significance of isolated hepatitis $B$ core antibody and the suggested management of patients. JAMC. 2001;165:1063-4.

10. Gibney KB, Torresi J, Lemoh C, Biggs BA. Isolated core antibody hepatitis $B$ in sub-Saharan African immigrants. J Med Virol. 2008;80:1565-9.

11. Van Damme P. Long-term protection after hepatitis $B$ vaccine. J Infect Dis. 2016;214:1-3.

12. Paxton GA, Sangster KJ, Maxwell EL, McBride CRJ, Drewe $\mathrm{RH}$. Post-arrival health screening in Karen refugees. PLoS One. 2012;7(5):1-7.

13. Pottie K, Greenaway C, Feightner J, Welch V, Swinkles H, Rashid M, et al. Evidence-based clinical guidelines for immigrants and refugees. CMAJ. 2011;183(12):E824925.

14. National Tuberculosis Advisory Committee. Position statement on interferon- $\gamma$ release assays in the detection of latent tuberculosis infection. Commun Dis Intell Q Rep. 2012;36(1):125-31.

\section{Copyright: (c) (i) (2)}

(c) $2018 \mathrm{Ngo}$ et al. This article is licensed under the Creative Commons Attribution-NonCommercial-ShareAlike 4.0 International Licence, which allows others to redistribute, adapt and share this work non-commercially provided they attribute the work and any adapted version of it is distributed under the same Creative Commons licence terms. See: www.creativecommons.org/licenses/by-nc-sa/4.0/ 